CHAPTER 12

\title{
Cine-Things: The Revival of the Emirati Past in Nojoom Alghanem's Cinemascape
}

\author{
Chrysavgi Papagianni
}

\section{$1 \quad$ Introduction ${ }^{1}$}

One of the first Emiratis to become a successful filmmaker and to boast an international reputation, Nojoom Alghanem ${ }^{2}$ is interested in stories that are on the verge of disappearance. From her very first film, Between Two Banks (1999), which tells the story of the last local man sailing between Dubai and Deira, the director has been intent on recovering the past: in her own words, the film was "almost like the last evidence of an era," especially if we take into consideration that the main character died soon after the making of the film. ${ }^{3}$ Indeed, a close look at films like Hamama (2010), Sounds of the Sea (2014), Nearby Sky (2014), and Honey, Rain, and Dust (2016) clearly shows her nostalgia for an almost forgotten pre-oil past.

Among these films, Hamama 4 stands out for its focus on objects from the Emirati past which

1 I would like to acknowledge the generous support of the Office of Research at Zayed University, U.A.E., which awarded me a Research Incentive Fund Grant for a project on Emirati women filmmakers. Special thanks are also due to my colleague, Dr. Hülya Yağcioğlu, for the illuminating discussions on thing theory that we had.

2 Starting as a poetess in the 1990s, Alghanem is also a filmmaker who has directed more than twenty films, shorts, and feature documentaries. Given that the first Emirati film only dates back to 1998, Alghanem's oevre is indeed pioneering.

3 Nojoom Alghanem, interviewed by the author, October 2016.

4 Hamama won the Special Jury Award at the Dubai International Film Festival in 2010, Best Documentary Award at the Arab Film Festival in Sweden in 2011, and was screened in prestigious regional and international festivals. It has become animated and enlivened due to their projection on the cinematic screen. As a matter of fact, the film can be seen as a repository of old stories where memory-infused objects claim center stage as Alghanem attempts to reestablish a lost connection with the Bedouin past. These objects, or the film's cine-things, are granted a life of their own as they are positioned within Alghanem's cinematic landscape. As these cine-things are isolated from their usual context and placed on a visual terrain, their relationship with human actors is radically revised: the essential proximity of the two invests the objects with a voice of their own, while simultaneously enabling viewers to see them anew.

The focus of the film is on an elderly protagonist, the 93-year-old Hamama, who resides in the city of Sharjah and who continues to practice the ancestral art of healing despite her age. As the film

also been publicly screened at the New York University and Sorbonne University in Abu Dhabi, garnering wide academic attention. Nevertheless, the film has not had a theatrical release not only because feature documentaries do not constitute the usual commercial theater fare for "shopping-mall theatres" but also because Emirati films in general have had limited theatrical visibility given that the country's filmmaking history is only two decades old. For a more detailed discussion of the reasons surrounding the reduced theatrical visibility of Emirati films, see Dale Hudson "Locating Emirati Filmmaking within Globalizing Media Ecologies," in Media in the Middle East : Activism, Politics and Culture, ed. Nele Lenze, Charlotte Schriwer, and Zubaidah Abdul Jalil (Cham: Palgrave Macmillan, 2017): 165-202; and Chrysavgi Papagianni "Re-Orienting the Gaze: Emirati Women Behind the Camera," in Reorienting with the Gulf: Film and Digital Media between the Middle East and South Asia ed. Alia Yunis and Dale Hudson (forthcoming from Indiana University Press). 
unfolds, it becomes obvious that the director presents Hamama as an emblem of the past or, to use Astrid Erll's term, a "carrier of memory," ${ }^{5}$ which is preserved through the medium of film so that the future of the past can be ensured. All in all, the film makes a strong statement that the pre-oil past can come to life by bringing together human and non-human actors, objects and people. Undoubtedly, when projected or reconstituted in such a way, the past can have a healing effect on the present.

Regarding the cultural significance of the film's staging of memory-infused objects, one needs to consider that Hamama does not only question popular perceptions about Emirati people but also unsettles discourses that foreground the marketability of the past and the formation of a national identity. By looking at the relationship between materiality, representation, and signification in film, I will propose that local Emirati films, through a focus on memory-objects, can actually counteract the annihilating forces of globalization and commodification that have transformed the cultural identity of the area into a marketable commodity, making the pre-oil past almost obsolete. From this point of view, it can be safely argued that Alghanem's film invests things with cultural significance in order to illustrate how the material world of the past can still have an important effect on the identity formation of the Emirati people.

Grounded on thing theory and memory studies, this chapter highlights the need for a remediation of the Emirati memory, which is made possible through a collection of memory-infused objects. In particular, I am taking my lead from Bill Brown's groundbreaking work, ${ }^{6}$ which questions the status of objects as silent counterparts of human actors and argues, instead, that there is a mutually informing relationship between the two. Brown further draws a distinction between objects and things, suggesting that the thingness of objects emerges

5 Astrid Erll, "Travelling Memory," Parallax 17, no. 4 (2011): 12.

6 Bill Brown, "Thing Theory," in Things (Chicago: University of Chicago Press, 2004), 4. when the latter "stop working for us," that is, when "the drills breaks, when the car stalls ... when their flow within the circuits of production and distribution is arrested, however momentarily."

When we look closely at the context of the United Arab Emirates (U.A.E), it becomes clear that objects signifying the pre-oil past, or what I called earlier memory-infused objects, have "stopped working" for the local people, or, rather, they have been halted due to the dramatic changes that occurred in the past fifty years and radical transformation of the material geography of the area since the discovery of oil. ${ }^{8}$ More specifically, oil has become a temporal signifier designating the pre- and post-oil era and has spearheaded radical changes in the lives of local populations. It has, in fact, become the driving force behind the union of the seven Emirates in 1971 and the economic power of the region as a whole. Thus, oil emerges as an allencompassing object defining and representing the newly-formed Gulf states and their citizens. However, due to the almost limitless possibilities for growth that oil created, objects from the past have either disappeared or, at best, have lost their original significance.

As a result of this sweeping transformation, the pre-oil past bears no similarities to themushrooming, industrialized cityscape-cum-marketplace reality of the present. As Brown argues, once objects stop working, their thingness, or their interiority, becomes evident and thus they are transformed into values and fetishes. Nevertheless, in the case of the U.A.E., it appears that the thingness of past objects is hard to emerge as the past itself has been banished from popular imagination, which is now dominated by the limitless possibilities for growth predicated on oil. To put it differently, there is no space for these objects to exist except, perhaps, when they are positioned as marketable

7 Ibid.

8 Oil was discovered in the 1950s and oil exports started in 1962. The modern state as we know it today was formed in 1971, when the seven Emirates came together and formed a federation 
commodities in souqs or as historical exhibits in museum windows, where they are nevertheless "muted." The things' displacement from traditional sites of identity formation parallels the displacement experienced by contemporary Emiratis and, at the same time, prevents these objects from triggering an emotional response from the Emirati people.

To make matters worse, objects of a global commodity culture circulate widely in a country that is characterized by rampant consumerism, to the extent that commodities often pose as supplements for rather than of people. Yet, these objects fail to turn into things because they are devoid of any cultural significance for modern Emiratis. The obvious aftermath of this cultural process is a sense of alienation that calls for an immediate redefinition of modern Emirati identity, which seems to rely more on the global reality of the present than on the memory of the past. Such a redefinition is achieved through Hamama as the film becomes a medium of localization ${ }^{9}$ that opens up a new space for memory-objects to meaningfully exist. ${ }^{10}$ Indeed, what Alghanem's cinematic landscape presents is the "before" of objects. ${ }^{11}$ As these objects become animated, their "after" also becomes possible since the memories that these objects evoke become mobile as they are rememediated through film. To remember Erll, "contents of cultural memory must be kept in motion, because they ... do not exist outside individual minds, which have to actualize and re-actualize those contents continually to keep them alive."12 This is what Alghanem's film achieves: it actualizes and

For a further discussion of locality versus globality in the Emirates see Chrysavgi Papagianni, "The Salvation of Emirati Memory in Nujoom Alghanem's Hamama," Quarterly Review of Film and Video 35, no. 4 (2018): $3^{21-}-32$.

That films can offer this space is an argument also put forth by memory studies, which emphasize the need for memory to become more mobile. See, for example, Erll, "Travelling Memory," 4-18.

11 Brown, "Thing Theory," 5.

12 Erll, "Travelling Memory," 13. re-actualizes the memory of the pre-oil past, keeping the past itself in motion, and thus ensures the preservation of this memory beyond the span of a mere viewing of the film.

\section{Discourses of Emirati Nationhood and Identity}

Overall, Hamama's nostalgic turn to the material culture of the past redefines contemporary Emirati identity that is nowadays presented, rather ineffectively I would say, through specific discourses of nation branding and popular stereotypes borrowing heavily from Orientalist attitudes and propagated by the overwhelming force of globalization. Before discussing how the film enacts such a turn, we need to look briefly at these discourses to better understand the significance of Alghanem's film. The obvious starting point would be the dominant stereotypes and the exoticism discourse that are intimately linked to an Orientalist rhetoric. In short, Orientalism posits the Orient as the "other" and thus sets the ground for the political and cultural hegemony of the West even after the presumed end of colonialism. ${ }^{13}$ Within this context, stereotypes, both positive and negative, support hegemonic power structures by describing East-West relationships through simplifying binaries.

With regards to stereotypes, one needs only to look at Jack Shaheen's work, ${ }^{14}$ which poignantly illustrates how perceptions about Arabs have crystallized in popular representations in films, magazines, and the news. Shaheen successfully reveals how the Western hegemonic discourses described Arabs either as absent or different by promoting stereotypical images of dangerous, incomprehensible

\footnotetext{
13 Edward W. Said, Orientalism (New York: Vintage Books, 1979).

14 See, for example, Jack Shaheen, "Reel Bad Arabs: How Hollywood Vilifies a People," The Annals of the American Academy of Political and Social Science 588, no. 1 (2003): 171-93.
} 
males or extremely conservative, exotic, or eroticized females. That these stereotypes still exert a strong hold on popular imagination becomes obvious if one looks, for example, at the 2010 film, Sex and the City 2 (SATC 2$)$, which supposedly takes place in modern-day Abu Dhabi, the capital of the U.A.E. ${ }^{15}$ The film crystalizes dominant perceptions of the area that are highly stereotypical and is but another example of a foreign film that is widely screened in the country, ${ }^{16}$ threatening to normalize the outsider's view and influence Emiratis' self-perceptions. In the words of Dale Hudson, the visibility and predominance of foreign productions allow "foreign suspicions to frame perceptions about the U.A.E."17 that are limiting and do not do justice to their people or the country.

As Elizabeth Ezra argues in her book, Cinema of Things, in $S_{A T C}$ the Middle East and, in this case, Abu Dhabi "appears stuck in an exoticism infused past."18 She goes on to explain that Abu Dhabi is shrouded in what Johannes Fabian has termed "allochronism," "a primitivist trope in which cultures located at a geographical remove from one's 'own' are deemed to inhabit a different temporal space."19 Thus, $S A T C_{2}$ is an eloquent example of a Western view of the East that is clearly tinted by past stereotypes and popular Orientalism. As such, it underlines the need for an internal point of view and highlights the importance of films like Hama$m a$ that resist such depictions.

Another popular discourse that dominates the film's narrative is that of extreme affluence whose apex is overconsumption. Images of extreme luxury and wealth feature prominently in $S A T C_{2}$, which capitalizes on a view of the country as a

\footnotetext{
15 The film was not actually filmed in Abu Dhabi but in Morocco due to cultural restrictions.

16 U.A.E. has the biggest box office of Hollywood films in the area. At the same time, Bollywood and, lately, Lolywwod productions screen widely in the U.A.E. theaters.

17 Hudson, "Locating Emirati Filmmaking," 173.

18 Elizabeth Ezra, Cinema of Things: Globalization and the Posthuman Object (New York: Bloomsbury Academic, 2017), 42 .

19 Ibid.
}

posh tourist destination. Hudson warns against such foreign media production that "obscures populations of middle-class Emiratis who do not keep 'exotic' animals as pets or drive gold-plated cars with special-number plates." ${ }^{20}$ Such representations build on popular Orientalist representations of petro dollars and oil-rich sheikhs and offer a narrow view of the forty-seven year-old nationstate based on models of transformation and modernization according to which the desert, and the Emirati past for that matter, have gradually disappeared under the push for ever-expanding cities.

The defining object signifying this dramatic transformation and ensuing modernization of the U.A.E. has been the oil. More specifically, discourses about change in the Middle East refer to the pre-oil and post-oil era, with oil posing as the quintessential object-cum-thing defining the modern state. From this point of view, oil lies at the heart of many popular representational discourses, having acquired a thingness that has become synonymous with the Arabs and the Arabian Peninsula itself. Interestingly enough, the discourse of affluence which is closely linked to oil and the notorious petrodollars seems to be promoted not only by the West but also by the countries of the area themselves. In the U.A.E.'s case, its two leading cities, Abu Dhabi and Dubai, invest heavily in nation branding in an attempt to package and sell an identity that can be easily marketed and consumed. In this context, identity is represented by an array of objects and practices that are intended for popular consumption and are, more often than not, linked to economic progress and a posh lifestyle.

To exemplify, Burj Khalifa has emerged as a fetish, an emblem encapsulating the quintessence of the country. Indeed, the tallest building in the world is among the most popular sites of tourist consumption, having acquired a life of its own in the popular imagination, both local and foreign. It has, in fact, come to represent all that the 
country has achieved in less than fifty years from its formation: it is an icon of progress, money-power, and prestige. Moreover, adjectives in the superlative describing the place seem to be part of a national campaign to advertise the country as the ultimate travel destination. Thus, "the tallest," "the fastest," "the most," "the only" are qualifiers that promote the country's exceptionalism. According to Robert A. Beauregard, Dubai poses on the global map as a "city of superlatives." ${ }^{21}$ Following the dictates of a global and local culture that are highly depended on things, nation branding has turned these landmarks into the epitome of Emirati nationhood and essential parts of its identity.

Apart from the two discourses mentioned above, nation branding in the Emirates promotes, among other things, the discourse of traditionalism, ${ }^{22}$ which explains the recent boom in heritage projects all around the country. Significantly, the seven Emirates, with Abu Dhabi, Dubai, and Sharjah in the lead, show a keen interest in promoting the local culture through conscious efforts to connect it to the local heritage. Hence the wealth of heritage clubs, villages, festivals, museums, and various other initiatives that aim at preserving the past. To mention only a few examples, the Emirates Film Competition and the National Center for Documentation and Research actively promote the Emirati heritage through projects such as the Sheikh Zayed National Museum or the annual Quasr Al Hosn Festival. ${ }^{23}$ At the same time, the

21 Robert A. Beauregard, "City of Superlatives," City and Community 2, no. 3 (2003): 183-99. Apart from Burj Khalifa, other identity features associated with the Emiratis are Atlantis The Palm Jumeirah (the sevenstar hotel with underwater suites in Dubai), the Burj Khalifa dancing fountains, and the impressive Emirati malls.

For a more detailed discussion on nation branding see, for example, Simon Anholt, "Why Brand? Some Practical Considerations for Nation Branding," Place Branding 2, no. 2, (2006): 97-107.

For more details on attempts at preservation by the U.A.E., see Fred Lawson and Hasan Al Naboodah, "Heritage and Cultural Nationalism in the United Arab pre-oil, Bedouin past comes to life through safaris that are, nevertheless, linked to a culture of consumerism, as luscious buffets, belly dancers, and luxurious comfort conceal the poverty of the past and the harshness of the desert life. During these safaris, even national identity can be "tried on" in the form of an abaya or a kandoura for the sake of photographs. This "touristification," although not within the scope of the present chapter, is definitely worth studying more as it obviously problematizes notions of Emirati identity that have become commodified. Some would argue that the past and its memory are repackaged and sold for profit. Nevertheless, this could also represent an attempt to link identity to concrete objects and artifacts not just for the sake of nation branding but also for the sake of cultural preservation and survival. Given that the U.A.E. is a newly-formed state in the process of solidifying its defining principles, such a narrative could, indeed, be linked to the need to forge a common identity for the seven Emirates that form the union.

Needless to say, this commodification of nostalgia is in sync with a commodity culture and globalized modernity that have swept over the Emirates. Unfortunately, even when it is not kindled for touristic ends and purposes, such nostalgia does not seem to suffice when it comes to the preservation of memories of the pre-oil past, especially given that the carriers of this memory, those above the age of sixty who have experienced this past past, are almost extinct. ${ }^{24}$ The transmission of stories from the past is further complicated by the oral tradition of the area and the ensuing absence

Emirates," in Popular Culture and Political Identity in the Arab Gulf States, ed. Alanood Alsharekh and Robert Springborg (London: Saqi Books, 2008), 15-30. According to the 2005 census data, adults older than 65 represented less than $3 \%$ of the total local population. More than ten years later, the number is bound to be even smaller. Cf. Statistics by Subject: Population by Age Group 1975-2005, Dubai, United Arab Emirates: Federal Competitiveness and Statistics Authority, 2016, http:// fcsa.gov.ae/en-us/Pages/Statistics/Statistics-by-Subject.aspx. 
of written records. At the same time, the younger generations are sated by overconsumption as they compete for the acquisition of more and more goods and opt for different narratives that are linked to the present, as Suleyman Khalaf aptly observes. ${ }^{25}$ Unfortunately, despite sincere attempts to salvage the past from the ruins of modernity and foster memory, these state-led efforts do not seem to suffice. This is undoubtedly the aftermath of the local conditions of memory rupture and discontinuity with the past, but, at the same time, it could also be linked to the death that objects suffer in museums due to their removal from their socio-historical context. ${ }^{26}$ From this point of view, their display in museum windows or during festivals falls short of triggering an emotional response in modern Emiratis. To put it differently, the lack of affect when it comes to the representation of these objects obscures their interiority and does not allow for their "magic" to emerge.

Things become even more complicated if we consider how the discourse of traditionalism often gets entangled with the other discourses mentioned above. For instance, the trade in mementoes and knick-knacks which, according to Ezra, also characterizes Western discourses of exoticism, is very prominent. ${ }^{27}$ This trade takes place both in the more traditional souqs and in the super-luxurious five-star hotels spread widely in the country. Take, for instance, the gawah, or Arabic coffee pot, which can be found everywhere, from museum windows to travel brochures to souqs to ostentatious hotel lobbies. It would not be far-fetched to argue, then, that the pre-oil past is de-territorialized and placed in sites that are

25 Suleyman Khalaf, "Globalization and Heritage Revival in the Gulf: An Anthropological Look at Dubai Heritage Village," Journal of Social Affairs 19, no. 75 (2002): 13-42. For a similar argument see also Jane Bristol-Rhys, "Emirati Historical Narratives," History and Anthropology 20, no. 2 (2009): 125. See Walter Benjamin, The Arcades Project, ed. Rolf Tiedemann and trans. Howard Eiland and Kevin McLaughin (Cambridge, MA: Belknap Press, 1999), 67. incongruous with what it represents, that is, a previous Spartan way of life. To put it differently, the humble, banal gawah does not seem to belong in a setting of extravagance and affluence. When this happens, the object loses its original meaning and "stops working for us." Even if its presence in this setting indicates an attempt to fit the gawah in the new reality of the country, it is this very reality that banishes it from the present due to its disconnection with the past. From this perspective, the reconnection and re-territorialization of these memory-objects becomes a necessity in a country that is left "stranded in a present without a past," as many commentators point out. ${ }^{28}$

\section{The Magic of Objects in Hamama}

The above discussion has focused on problems and limitations inherent in popular representations of the Emirati culture and has underlined the failure of current preservation efforts to create a meaningful bridge with the past. Vis-à-vis these shortcomings, the remediation of Emirati memory from oral accounts in Alghanem's cinemascape establishes an essential interconnectedness between the past and the present that challenges dominant representational paradigms. Indeed, a close look at the film shows that the staging of neglected memory-objects from the Emirati past reveals their true meaning and thus enables their subsequent preservation for future generations. To put it differently, memory-infused objects are transformed into living things that complement the characters living in the present in a harmonious and necessary way. Along this axis of complementarity, an essential proximity between people and objects is established, and a dialectical relationship between human and non-human actors is foregrounded. All in all, this new visual relationship can lead to a redefinition of Emirati identity

28 See, for example, Papagianni, "The Salvation of Emirati Memory," and Bristol-Rhys, "Emirati Historical Narratives." 
as the "pre-oil" and "post-oil" eras are brought together in ways that can fight against the epistemic closure of the Emirati past.

My discussion of the film is partly informed by Arjun Appadurai's view in The Social Life of Things, where he posits that, methodologically, "it is the things-in-motion that illuminate their human and social context," despite the human actors' need to "encode things with significance."29 Starting from this premise, I will "follow" the objects in Alghanem's films in an attempt to show that these objects surpass, to use Brown's words, "their mere materialization as objects, or their mere utilization as objects," 30 turning into values and memories laden with possibilities as far as the salvation of Emirati memory is concerned. The focus on the "magic" of objects in Hamama also relates to discussions about early cinema's obsession with the power imparted in objects. ${ }^{31}$ For instance, in 1924, the French film theorist and filmmaker Jean Epstein addressed the ability of the cinema to convey a "semblance of life to the objects it defines" that essentially invests those objects with "personality."32 Interestingly enough, a century or so later the need to refocus on objects and their "magic" seems to resurface as the redrawing of boundaries between people and objects has become a central concern in a globalized and highly commodified world. ${ }^{33}$

As far as the film is concerned, the choice of an elderly protagonist is in sync with Alghanem's nostalgic turn to the Emirati past in an attempt to recuperate it. Indeed, the almost blind protagonist

29 Arjun Appadurai, "Introduction: Commodities and the Politics of Value," in The Social Life of Things: Commodities in Cultural Perspective, ed. Arjun Appadurai (Cambridge: Cambridge University Press, 1986), 5 .

$30 \quad$ Brown, "Thing Theory," 6.

$3^{1}$ Rachel O'Moore, Savage Theory: Cinema as Modern Magic (Durham: Duke University Press, 200o).

32 Jean Epstein, "On Certain Characteristics of Photogénie," in French Film Theory and Criticism, Vol. I: 19071929, ed. Richard Abel (Princeton, NJ: Princeton University Press, 1988), 116. embodies the pre-oil past since she is a genuine "carrier of memory" who, in line with Erll's definition, "share[s] in collective images and stories of the past, who practice[s] mnemonic rituals, display[s] an inherited habitus," and can rely on a gamut "of explicit and implicit knowledge."34 As a respected healer, Hamama exhibits throughout the film profound implicit and explicit knowledge of how to concoct medicine and heal people, both of which come from an ancestral past.

As the camera follows her around, we can see Hamama performing her daily chores in the house and on the farm. These chores depend upon her use of specific objects that are evocative of past routines and rituals, which Alghanem brings to life through the medium of film. An apt example is the vessel used to make cheese, which plays an essential role in Hamama's life. Without it, she cannot function, she cannot even survive. It seems that the object has become an integral part of her existence, an extension of the self. The vessel is invested with a significance that one cannot miss as the camera closes in on it. It is as if it has a life of its own, a symbolic depth, as it is connects to a different temporal dimension. The object stands for the self-sustained way of life of the pre-oil era, which has been replaced by mechanized food production after the discovery of oil.

Hamama is by no means a detached observer as a museum visitor might be. Instead, she is involved in meaning-making as she carries the vessel with an inherited habitus that allows her to reveal its hidden meaning, the "magic" of the object. Presented in a dialectical relationship with the main character, the object emerges in its full potentiality, becoming a supplement of the human actor. It is this close proximity of human and non-human actors that informs what I call Alghanem's "thing rhetoric," which usually occurs through close-ups on everyday objects, such as the cheese vessel and the sleeping rug, and on fetishized objects, such as Hamama's water dripping hands. This thing rhetoric is reiterated in Alghanem's film through scenes

Erll, “Travelling Memory,” 12. 
illustrating the possession and raise of animals, the making of cheese, or the ancient healing practices mentioned above.

Similar to the cheese vessel, the rug becomes a signifier of an older mode of existence characterized by poverty, simplicity, and self-sustenance. Hamama's preference for the rug is, once again, indicative of the intimate relationship between the object and its owner. The rug is her object of choice and a companion that allows her to be in close proximity to the earth and the sand, both of which are quintessential to her identity. The rug becomes an extension of Hamama as it encapsulates the simple lifestyle of the Bedouin past. As we see her opting for this past against the comfort of the present (i.e., the rug vs. the bed), we are reassured that the past is not to be dismissed: it is still a valid lifestyle choice. Imagine now the rug displayed in a museum or in a souq. It would pose as an exotic object or as a collectible commodity. An Emirati youngster could pass by and ignore it because it would be devoid of reference and lack affect. In contrast, the memory-objects in Alghanem's films are rendered in "quotidian moment[s] of banality" 35 and are invested with affect, having the ability to elicit both sensory and gestural attention not only from the camera and Hamama herself but also from the viewer. Looking at the image of the Maltese falcon, Lesley Stern argues, for instance, that "the affect of the moment is the ability of the image to elicit from us a sensory response. This quotidian moment is also a moment when the gestural and the object are brought into relationship, when the thing elicits gestural attention. Or perhaps it is the other way around: gestural attention elicits a certain quality of thingness." 36 Obviously, the

35 Lesley Stern, "Paths That Wind through the Thicket of Things," in Brown, Things, 397. Stern looks at how cinema invests things with affect and discusses "the quotidian nature of things as a mode of cinematic instantiation" (399). Bill Brown, A Sense of Things: The Object Matter of American Literature (Chicago: University of Chicago Press, 2003), 397. cheese vessel and the rug elicit a sensory response from Hamama. The gestural attention she pays to these objects is indicative of the intimate relationship she shares with them, which, in turn, calls for a similar attention from the viewer. In accordance with Stern's view, the image of the object or the ritual associated with it elicits from the spectator a sensory response that is similar to Hamama's. The "affect of the moment"-be it a gesture or a feeling - can thus escape the screen and survive into the future as a concrete memory of things past.

To bring this point home, an intense feeling of nostalgia emerges as the camera casts an affectionate glance at the humble vessel or the trivial rug which, nevertheless, represent the cornerstone of Hamama's world. In line with Stern, both these objects participate in "different temporalities: narrative time and emotional duration (the temporality of touching)." 37 This double participation surfaces as they occupy a central place in narrating Hamama's story: both the film's mis-en-scène and the things themselves simultaneously evoke nostalgic feelings for a previous mode of existence in the audience. To put it differently, the staging of the cine-things encapsulating the past contains gestural tropes like preparing food, eating, sleeping, farming, or healing that are reminiscent of older times.

As Stern posits, the transformation of objects into actions is what really attracts the viewers' attention. Starting from a similar premise, Robert Bresson argues that the gestures that objects initiate can represent the real substance of films. ${ }^{38}$ This is true as far as Hamama is concerned if we consider, for example, that the materiality of the film re-creates rather than merely re-present the Emirati self. The cultural significance of Algahanem's films is in sync with what John Plotz calls "culturalist object theory," a notion which underlines the symbolic dimension of evocative objects

\footnotetext{
37 Ibid.

38 Robert Bresson, Notes on the Cinematographer, trans. Jonathan Griffin (London: Quartet Books, 1986), 59.
} 
through which cultures represent themselves. ${ }^{39}$ Although culturalist object theory has been questioned on the grounds that such an approach attaches a pre-determined meaning to objects and precludes the possibility of their speaking for themselves, ${ }^{40}$ from an Emirati perspective, the memory-objects' capacity to speak is inhibited not because of their silencing but because of their belonging to an almost-forgotten past. Thus, when it comes to salvaging the past within specific sociocultural conditions, the culturalist object theory is still a fertile methodological approach.

The "magic" of objects in Hamama draws attention not only to concrete objects but also to processes and actions involving the material world, such as animal farming and cheese making, which illuminate the objects' social context. If one takes into consideration the radical transformation of the material geography of the U.A.E. in recent times, the scenes where Hamama visits her farm and interacts with the animals vividly bring to life memories of the past. More specifically, "as modernity banished the desert from the social imaginary and substituted the camel with the Ferrari,"41 people's connection to space and locality has been compromised. Admittedly, many modern Emiratis own farms and regularly visit them for family gatherings. However, they rely on hired help for farming and maintenance, so their relationship with a locale that used to be the cornerstone of their life in the past is no longer interactive. Emiratis are simply visitors to these sites of identity formation.

John Plotz, "Can the Sofa Speak? A Look at Thing Theory," Criticism 47, no. 1 (2005): 110. Plotz discusses how anthropological discourses consider evocative objects to examine the ways in which a culture describes itself to itself. According to Plotz, such a culturalist object approach is limited because it does not allow objects to speak for themselves. Plotz's approach to thing theory as an investigation of the margins of meaning rather than symbolic objects, or "marked up signifiers" (112) is interesting, yet it might not be applicable to cases where salvaging of memory is needed. Ibid.

41 Papagianni, "The Salvation of Emirati Memory," 327.
Alghanem reconstitutes this lost connection through scenes where the elderly protagonist, despite her age, participates actively in animal farming. Even more, Hamama talks affectionately to animals, which she knows by name. Clearly reminiscent of the intimate relationships that people used to share with their locale in the past, these scenes also reveal the affectionate relationship between animals and Hamama. The animals elicit gestural attention and, thus, they are also invested with affect.

In these scenes, Alghanem opts for long shots, thus creating a sense of communal space in which the human actor does not dominate the setting. In fact, through these long takes, the focus is on the material environment, the locale, and the state of things, which complement Hamama in a harmonious way as the elderly protagonist obviously "belongs" to this environment. The setting and the things are central to the narrative, to Hamama's life, and to reconstructing the past. It could be argued at this point that Alghanem's cinematic language supports the thing rhetoric of the film. Indeed, through the use of long shots, slow motion, close ups, and crosscutting, the material world of the past is re-appropriated in a more intimate and personal way that makes the cine-things resonate with life. As a result, "things seem slightly human and humans seem slightly thing-like" 42 as they mutually shape and even occupy each other. To exemplify, the elderly protagonist is reified through the use of extreme close up on her hands in the scene where she touches the water falling onto the plants, a gesture which turns her hands into a fetish. At the same time, the slow-motion technique fetishizes the water itself, which turns into drops on Hamama's hands. In these scenes, the material object and the fetishized body are brought together harmoniously, appearing as almost inseparable. Alghanem's choices are obviously a result of her poetic sensibilities. At the same time, they are also part of her agenda of salvaging the memory of preoil era through a focus on the things that made up

42 Brown, $A$ Sense of Things, 9. 
that world. As I have argued elsewhere, ${ }^{43}$ if one takes into consideration that water in the dry, desolate landscape of the desert symbolizes life, then Hamama's hands acquire a similar significance not only due to their healing potential but also as emblems of a past that relied exclusively on manual labor for survival.

Overall, the film abounds in moments when the camera closes in on Hamama's hands. This is the case, for example, in the scenes where she makes plant-based ointments, cooks, or touches the bodies of the people she heals. The fetishization of the elderly woman's hands, which become emblems of the past with the marks of time on them clearly captured by the camera, elicits once again a sensory response from the audience. At the same time, apart from the affective dimension highlighted here, the film also insists on the physical dimension of Hamama's hands as they "transmit" the wisdom of the past and heal the bodies they touch. This past, the film seems to say, needs to be acknowledged and respected." ${ }^{44}$ And indeed, not only is the past acknowledged thoughout the film but also reconstituted as a living presence as the magic of objects is constantly foregrounded.

It is interesting to observe that the recuperation of memory-objects in Hamama is often realized through a juxtaposition of the material world of the past and the present. If we see this recuperation through the lens of thing theory, what Alghanem does is a disavowal of the objects and practices related to modern commodity culture in favor of memory-infused objects that have no exchange value in terms of currency; instead, as the filmmaker seems to suggest, they can be traded for the past. To be more specific, the film shows a consistent preference for objects and practices of the past, which could be seen as a rejection of global capitalism and the discourse of affluence itself. As we have seen, the bed is shunned for the rug, and a self-sustained existence is preferred despite the presence of maids and hired help. This

43 Papagianni, "The Salvation of Emirati Memory," 328.

44 Ibid. juxtaposition of the past and the present is also obvious in the sequences where the bulldozer is working to make a new road behind Hamama's house. While the rug and the cheese vessel occupy a central place in the narrative, eliciting Hamama's affect, the bulldozer associated with global capitalism seems to occupy an awkward space of nonbelonging. The image of the bulldozer is incongruous with the affectionate reality established in the scenes described above, where a sense of reciprocity and complementarity between the human and the social context surface beautifully. For example, in the scenes where Hamama stares blankly at the bulldozer, the human and the social context are inharmonious. Instead of affect, the bulldozer elicits from Hamama feelings of fear and disdain. A symbol of a new order of things brought about by oil, the bulldozer threatens to irreversibly change Hamama's way of life and obliterate the past.

Moreover, although the film does not focus on oil per se, the changes and tensions that its discovery have generated are visualized clearly in such moments. It is this new order of things that illuminates the thingness of oil as a perennial presence in the film. Even when Hamama is inside her house, shielded from the outside world, oil materializes in the form of foreign maids and helpers, modern furniture, and knick-knacks. While Hamama does not seem to be aware of or influenced by their presence as she remains loyal to the old ways, outside the house she feels the threat that oil carries as an agent of modernity and change. Yet another materialization of oil, the bulldozer threatens to transform the outside world as she knows it and this, as she tells her grandson, endangers the children. Hamama here expresses a clear concern about the threat that modernity poses to the younger generation.

It is interesting to note that Hamama uses the sleeping rug over and over again to sleep outside at night in scenes where she attempts, one could argue, to safeguard her place from the encroachment of modernity represented by the bulldozer. It is as if the rug becomes her shield against 
erasure, an inherited habitus that bespeaks of her determination to carry on. Thus, Hamama is by no means compliant. Her sleeping outside the house can be regarded as an act of resistance against displacement and obliteration. As she practices her routine, the rug loses its value as an object and becomes one with her, defining her "Emiratiness" and, thus, her belonging to a specific locale. The fact that the rug allows her to sleep on the sand ensures a strong connection both with her Bedouin past and the setting, given that the sand is an integral part of local identity. Conversely, the bulldozer is responsible for the burial of the sand under cement, that is, for the transformation of the material geography of the area, which also implies an obliteration of the past by the present. Thus, the rug becomes an extension of a past that lays a bold claim on the present. The crosscutting between the blissful scenes of everyday life inside the house and on the farm and the unnerving scenes of the bulldozer brings this point home as it highlights the discrepancy between the two. Hamama's silence as she stares at the bulldozer is indicative of the incompatibility between the old and the new world. Simultaneously, "silence emerges as a powerful trope of resistance," 45 as an act of defiance and disregard. In this sense, Hamama the protagonist and Hamama the film turn into guardians of these memory-objects that are in danger to be lost as progress intrudes upon daily life.

Despite the juxtaposition and occasional polarization between the material world of the past and that of the present discussed above, it should be noted that the film also highlights an essential intersection between the two. This is clearly illustrated in the scenes where Hamama uses plants and ointments from the past to treat people. The ancient practice of healing is acknowledged and given its due respect in the film, as we see people from near and far coming to Hamama for help. The fact that many of these people are young and, thus, accustomed to the latest, state-of-the-art hospitals and modern methods of treatment enhances

45 Ibid., 329 . the aura of reverence surrounding this ancestral healing practice. At the same time, the presence of a doctor that acknowledges the importance of these practices validates them and opens up space for their inclusion in the present. It is in these scenes that Alghanem establishes very clearly the interconnection between the past and the present as the two are shown to mutually inform each other. Both the doctor, a representative of modern practices, and the young people, who inhabit a post-oil space of affluence, embrace the old ways and in so doing bring them into the present. Their affective response to the past during these scenes extends beyond the screen, to the audience.

Once again, the bowl used to mix plants and other ingredients for the medicine is invested with an affect that brings to mind Brown's description of objects that are no longer used merely as objects. Instead, they gain a "force as a sensuous presence or as a metaphysical presence"; 46 this is where their magic comes from. The magic of the bowl in the film is not just linked to the healing effect of the medicine it is used to produce. It is further and most importantly linked to it belonging to an old time, to a past that is almost forgotten. In this respect, the bowl is not just a bowl: it is a memory-object that has a metaphysical presence as it carries within itself the values of a different temporal dimension. Once again, the reciprocity and proximity of the bowl and the human actor brings out the magic of the object and ensures the transference of the values it embodies to the present.

Overall, the staging of everyday objects from the past within the film-scape places Alghanem into the role of a collector. From this point of view, "the film can be compared to a 'museum' of localized memories, full of images, sounds, and colors that can awaken the Emirati spectator to a new sense of selfhood." 47 In his introductory chapter to Things, Brown asks a crucial question: "How does the effort to rethink things become an effort to

\footnotetext{
46 Brown, "Thing Theory," 5.

47 Papagianni, “The Salvation of Emirati Memory," 328.
} 
reinstitute society?"48 The answer can be simpler than we imagine, especially if we take into account Baudrillard's assertion that, through the collection of objects, "it is invariably oneself that one collects." ${ }^{49}$ Collecting and recollecting the "Emirati self" in order to salvage the past and thus reinstitute the Emirati society seems to be exactly what Alghanem does in Hamama.

The question that obviously arises at this point is whether Alghanem urges for a return to the past or not. The answer is not simple, especially considering that a return to the past would not help the country survive into the future. It could be argued, then, that Alghanem attempts to salvage the past from obsolescence. In doing so, she further underlines the incongruity of the various discourses that represent the Emirati people and the Emirates and offers a new representational paradigm, perhaps a fourth type of discourse, one that brings the past into the present. As she has invariably stated, her interest lies with the past, as well as with the present and the future. ${ }^{50} \mathrm{~A}$ look at her oeuvre from the perspective of thing theory shows that the nostalgic turn to the past does not preclude the present. Her focus on materiality brings forth the past

\footnotetext{
48 Brown, "Thing Theory," 9.

49 Jean Baudrillard, "The System of Collecting," in The Cultures of Collecting, ed. John Elsner and Roger Cardinal (London: Reaktion Books, 1994), 12. 2016.
}

not just as a temporal dimension but also as a lived experience, thus reconstituting its spatiality. All in all, the dialectic relationship between the memory-objects of the past and the human actors of the present is indicative of her attempt to create bonds between different temporal landmarks and thus make the future of the past possible.

Therefore, a close look at the cine-things "collected" in Hamama reveals that they are by no means "mute counterparts" in the story. In fact, it is through these things that the story of Hamama and of the Emirati pre-oil past is told. ${ }^{51}$ At the same time, these objects are stories in the making: they are symbols of times past that have been denied a narrative space due to the complete transformation of the material geography of the country. Obviously, the stories these objects tell are considerably different from the stories that official discourses promote. As a result, they have the ability to create a new basis for thinking of an Emirati identity. Needless to say, this comes at a very appropriate time for Emiratis. Indeed, at a time when the country is investing heavily in the future through the building of a city on Mars in 2117, salvaging the past from the assault of late modernity is more important than ever.

\footnotetext{
$5^{1}$ The ability of objects to tell stories is discussed by Mieke Bal in "Telling Objects: A Narrative Perspective on Collecting," in Elsner and Cardinal, The Cultures of Collecting, 99 .
} 